\title{
External Auditing in Improving Straightforwardness and Responsibility for The Sustainable Development Goals
}

\author{
Septiana Dwiputrianti ${ }^{1}$, Widya Nugraha ${ }^{2}$ \\ Polytechnic STIA LAN Bandung, Jalan Hayam Wuruk No. 34-38 Bandung 40115 ${ }^{12}$ \\ \{septiana.dwiputrianti@poltek.stialanbandung.ac.id ${ }^{1}$ \}
}

\begin{abstract}
Indonesian Supreme Audit Institution (ISAI/BPK) is currently examining the auditing implementation of Sustainable Development Goals (SDGs). BPK is one of the SAIs that has moved forward regarding the SDGs audit among other members of the International Organization of Supreme Audit Institution (INTOSAI). Unfortunately, the definition of the SDGs audit has not been mutually agreed upon. BPK also gave an example that in the SDGs preparedness audit, BPK used GIS and Gephi to assist the audit in deepening the root cause by using GIS to determine the right sample and using network analysis to prove hypotheses about expenditure realization that still needed to be improved in terms of quality. This study contributed to an understanding of how to communicate the SDGs audit at this stage, and how BPK plays a part in carrying out its work of supporting the goals of the state by utilizing a comprehensive SDGs audit model.
\end{abstract}

Keywords: External Auditing, Transparency, Public Accountability, audit SDG's

\section{Introduction}

The declaration of the 2030 Sustainable Development Goals (SDGs) in 2015, is inseparable from the Millennium Development Goals (MDGs) agenda, which was initiated by the United Nations in 2000, which aims to eradicate poverty, hunger, epidemics, illiteracy, environmental degradation, and discrimination against women. By carrying out 17 more agendas, the SDGs program is expected to be able to solve problems that have not been resolved in the previous program. The benchmark for the success of the SDGs program lies in its agenda, proposed for adoption by United Nations member countries by sharing a blueprint with great goals towards world peace and prosperity for all mankind, from the present to the future.[1]

As one of the member states of the United Nations, Indonesia participates in implementing the agenda, by synchronizing the blueprint of the SDGs agenda initiated by the United Nations, with the national mid-term development plan (RPJMN). Nawacita, as a reference for the national development agenda which is translated as the main guideline for the 2015-2019 RPJMN to the 2020-2024 RPJMN, aims to improve people's welfare. This goal is actually in line with the Sustainable Development Goals (SDGs) [2]. 


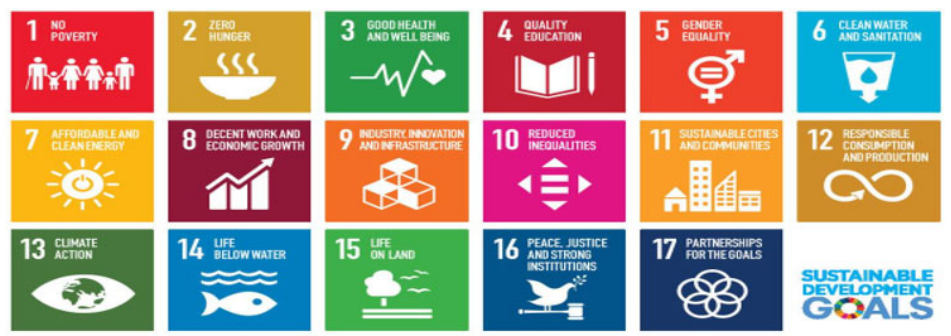

Fig 1. 17 agendas of the Sustainable Development Goals (Source: https://sdgs.un.org/goals)

With a massive and incessant follow-up to the SDGs agenda in various UN member countries, causing concern regarding the transparency of the budget disbursed, because of this, the International Organization of Supreme Audit Institutions (INTOSAI) was present as an independent organization whose mission is to support financial audit institutions related to good governance, improving audit quality standards and exchanging ideas, knowledge, and innovations related to financial audits.

The Supreme Audit Agency (BPK), as the agency tasked with conducting budget audits, is involved in the process of overseeing budget distribution related to the implementation of the SDGs program. The audit carried out by BPK began in 2018, by synchronizing with Bappenas, as the planner of the SDGs program in Indonesia. In conducting audits, BPK often innovates to solve external audit problems, due to the absence of a primary reference for external audit of the SDGs globally.

On this occasion, the author will explain the general standards and definitions of SDGs audits that were initiated by INTOSAI as the association of global financial audit institutions, and explain the methods and innovations developed by BPK in conducting external audits of SDGs, as well as their role in supporting the program in Indonesia.

\section{General Standards for Implementation of the SDGs}

INTOSAI Professional Standards Announcement is an official and official announcement or statement from the INTOSAI Community. They take advantage of the INTOSAI members with collective professional expertise and official statements provided by INTOSAI regarding matters related to the audit. The statements are compiled, all of which are then numbered and grouped according to their status and purpose in one structure [3].

INTOSAI Framework of Professional Pronouncements (IFPP), grouping professional pronouncements into three categories:

a. INTOSAI Principle (INTOSAI-P)

The principles applied by INTOSAI are divided into basic principles and core principles. The underlying principles have historical significance and form the definition of role and function, the ideals of which SAI should apply. The principles contained therein can serve as information for the Government and Council members, as well as SAI and the wider community, and can be used as a reference in establishing a national mandate for SAI action. The fundamental principles of SAI, which are supported by core principles, clarify the role of SAI and its position in society as well as a high-level prerequisite for carrying out its functions properly and behaving professionally. 
b. International Standards for the Supreme Audit Agency (ISSAI)

ISSAI is an international standards association that is authoritative in the implementation of public sector audits. ISSAI has objectives which include:

- Checking the audits carried out

- Strengthen the credibility of audit reports for users

- Increase the transparency of the audit process

- Sorting and determining the auditor's responsibilities to other parties involved

- Interpret various types of audit work and a set of related concepts that provide a common language for public sector audits.

ISSAI's complete structure is based on a set of fundamental concepts and principles, interpreting public sector audits and their various types of engagement, supported by ISSAI.

c. INTOSAI Guidelines (GUID)

INTOSAI develops manual guidelines to support the sustainability of SAIs and individual auditors in:

- How ISSAI practices are applied in the implementation of financial, performance, or compliance audit processes.

- How other involvements in ISSAI are put into practice.

- Understand the application of ISSAI relevant to the certain subject matter.

\section{Definition Implementation Audit of SDGs}

The implementation Audit of SDGs is an audit of the implementation of a series of policies that contribute to achieving national-level agreements targets related to single or multiple targets of the SDGs. This audit summarizes improvement of the achievement of targets that have been nationally agreed; and the probability of hitting the target as measured by the current trend; and adjustment of SDGs targets to the level of achievement of national targets.

The implementation of audits in the sustainability of the SDGs needs to use a comprehensive approach in governance in its implementation. Integration and continuity in the application of policies, and the extent to which the audit can cover the objectives, it is necessary to seek conclusions, as well as possible questions for the SAI auditor to conclude.[4]

\subsection{Principle Leave No One Behind (LNOB)}

The most important principle in implementing the 2030 SDGs agenda is Leaving No One Behind (LNOB). In the implementation of the agenda, the aspects of "Going Far Ahead" and "Leaving No One Behind" are highly emphasized in every action, recognizing the need to fight poverty and inequality. Nothing will be left behind, is an agreement and a collective effort that was mentioned earlier. The fundamental thing is the dignity of the human person which must be recognized, and all segments of society and the nation have a target and a goal that must be met. And the thing that is furthest first is the thing that must be achieved first.

In explaining 'Who is left behind, those who have neither the choice nor the opportunity to participate and take advantage of the development progress process are parties in this context. Those who suffer from deprivations or losses that cause limitations in their choices and opportunities relative to others in society, such people are thus considered and classified as 'underdeveloped' because they live in extreme poverty. 
The contents of the 2018 UNDP discussion paper have identified five main factors that cause communities to fall behind.

a. Discrimination: is the bad treatment of intentional discrimination against groups related to certain interests, usually, this is related to ethnicity, sex, and age, social class, sexual orientation, disability, religion, migration status, nationality, customs, etc.

b. Geography: Everyone who experiences a lack or loss of internet, public services, transportation, or gaps in infrastructure access to their homes who experience vulnerability and isolation.

c. Governance: Where people suffer losses due to injustice, ineffectiveness, unresponsiveness, and unaccountability of sub-national, national, and global institutions; Anyone whose life is affected by unfair, inadequate, or unresponsive processes, policies, budgets, or laws that are created or enforced or enforced; Anyone who is less able or unable to get the opportunity to express aspirations and participate in decision-making or elections that affect the lives of many people, and does not get to participate in the implementation of elections.

d. Status on Socio-economic: Any person who suffers a loss or deficiency in terms of educational attainment, income, and life expectancy; Anyone with very few opportunities to obtain nutritious food, adequate education, live a healthy life and find a decent job, clean water, energy, sanitation, social security, financial services, quality health care and/or wealth.

e. Shocks and vulnerabilities: Anyone who is more likely to be affected and/or vulnerable to the effects of violence, health emergencies, displacement, conflict, natural disasters, climate change, price declines, economic downturns, and/or other shocks.

People among these factors face weaknesses and discrimination that amplify and exacerbate their situation so that they tend to be the most disadvantaged. Audit targets related to the SDGs that have been agreed nationally, in the actions taken by the central government to apply the principle of 'leaving no one behind in the implementation of the SDGs can be examined by SAI. Actions to prioritize outcomes for vulnerable groups, as well as conduct monitoring beyond the population average to identify their specific needs, where they are, and who they are, are the scope of the examination. The selection of audit topics and/or conducting an examination of the principles in the LNOB as part of an audit of one of the national targets covering cross-sectoral issues can be considered by SAI concerning the LNOB principles.

The inspection conducted by SAI considers the following aspects:

a. How to identify disadvantaged groups and vulnerable groups?

b. What are the main reasons for their vulnerability and who is left behind?

c. What specifications of the data are available and what are the data shortages?

d. What actions are being taken to determine the needs of the disadvantaged and vulnerable?

e. What empowerment measures are implemented in support of vulnerable groups?

\subsection{Engagement of Multi-Stakeholder}

The implementation of inclusive and participatory follow-up in all implementation processes covering all levels starting from civil society, parliamentarians, national human rights institutions, the private sector, and the government sector, is one of the principles in the SDGs 2030 agenda. Recognition of stakeholders' interest as a very valuable partner in increasing public awareness and follow-up on the implementation of goals is an action to revitalize the core of sustainable development in the partnership of the SDGs 2030 agenda. Providing opportunities for groups directly or indirectly affected by the decisions taken, to be able to 
express their interests and needs them and support the government in implementing, adapting, and reviewing public policies, is a form of promoting effective decision-making rather than stakeholder participation. Implementation of the SDGs with a whole-of-society approach through participation and consultation has contributed to building a sense of belonging to the SDGs 2030 agenda. During the process of designing, following up, monitoring, and evaluating the review of the SDGs 2030 agenda, stakeholders are asked to be actively involved in it.

With the involvement of stakeholders, the integration process and policy coherence can be improved by delivering a deep and precise understanding of the problem, besides being able to identify better solutions from the policies made and being able to obtain implementation efforts accompanied by feedback. certainly, can help implement the agenda, given the complexity of the SDGs agenda and the interconnectedness of several targets in it. In the pre-design stage through public consultation, the stages of making and formulating policies, developing social partners to specify service areas, and carrying out monitoring, reviewing, and evaluation roles, are the scope of stakeholder involvement.

Conduct public consultations on draft laws when legislative changes are needed, provide assistance from NGOs and religious bodies to assist the government in serving and assisting the poor, seek feedback from academics regarding the required efforts and deficiencies in them, and dissemination satisfaction survey of the poor regarding the use of services and services provided is an example of stakeholder participation in audits that focus on national-scale poverty reduction efforts.

In determining and following up on targets that have been agreed nationally within the framework of the SDGs agenda, SAI's mandate mentions inspections related to 'multistakeholder engagement', as an examination of the government's efforts to involve and reach out to many stakeholders. Sufficient interaction, level of stakeholder involvement, critical stakeholder involvement, and creating appropriate conditions for engagement are forms of auditor examination of the government. A feedback system that allows for multiple exchanges and negotiated dialogue, a feedback system that is accessible and uncomplicated for stakeholders, a communication channel that allows for open and honest feedback, is a consideration in auditing regarding sufficient interaction.

Audit focus on national EIPV targets covering various entities such as ministries, perpetrators, victims, victim support groups, religious institutions, legal professionals, media, national statistical offices, civil society organizations (CSOs), service providers, United Nations Agencies, private sector, academics, and experts, among others, are the stakeholders considered involved. Identify the form of a partnership formed for the implementation of the SDGs, assess the extent and how to integrate stakeholder feedback into policy implementation and planning, identify the consultation process between key stakeholders who are not involved with other stakeholders, consider the available mechanisms and platforms and used in stakeholder engagement is the auditor's task in determining the level of involvement, whether it is adequate or not.

Due to the nature of the audit definition which tends to be flexible, BPK as the auditor continues to develop innovative audit analysis methods that are appropriate and able to cover audit implementation in various situations and conditions. The next section will explain the innovative analytical methods used by BPK in conducting audits. 


\section{SDGs Readiness Audit and BPK Audit Analysis Method}

In the report on the results of monitoring the readiness of the implementation of the SDGs agenda in Indonesia, the results contained in the audit show that the Government's actions are quite effective in preparing for the implementation of the SDGs. The government has demonstrated the ability to adapt the SDGs and synchronize them in national-scale planning, as described below:[5]

a. the government has invited and involved stakeholders to harmonize the SDGs agenda into national planning and has issued Presidential Regulation No.59 of 2017 to establish institutional management and integrate 94 global targets into the 2015-2019 National Medium-Term Development Plan (NMDP/RPJMN).

b. the government has identified the sources of funds and financing needed for the implementation of the SDGs in Indonesia, as well as monitoring and reporting procedures. The government has also established a mechanism to ensure the allocation of funds for the 94 SDGs targets included in the NMDP priorities and the preparation of accountability reports. In addition, the Government has also identified the capacity of non-financial resources in reporting, monitoring, and supporting implementation.

c. The government has established a plan to assign responsibilities to follow up, monitor, report progress, and review the implementation of the SDGs. In addition, the government has set baseline indicators, performance, and milestones to report, evaluate, and monitor the implementation of the SDGs; it has established processes to ensure data availability, data disaggregation rate, and data quality. Reporting, review, monitoring, and follow-up are designed through a participatory process involving stakeholders.

However, there are still improvements in some spaces as described below::

a. There need to be improved mechanisms throughout the government cycle to ensure the sustainability of the SDG program

b. Budget and Expenditure Policies need to be established to promote the quality of government spending.

c. Disaggregation of statistical data at the city and city levels cannot be generated.

Subsequently, the examination carried out by the BPK leads to the realization of the targets of the State of Indonesia as contained within the Prelude to the 1945 Constitution, namely to secure the whole Indonesian country and the country of Indonesia, and to make strides the common welfare, to teach the nation's life., and take part in advancement. the realization of world arranges based on opportunity, unceasing peace, and social equity. The implementation of the 2030 Agenda is very important because the 17 objectives of the Agenda are interrelated and can be a catalyst for achieving the country's goals. As one of the institutions in Indonesia, BPK's mission is to support the achievement of these goals.

The Supreme Audit Agency (BPK) has a strategic position in the hierarchy of the Indonesian government structure.

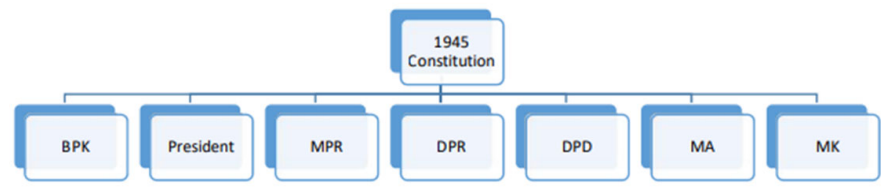

Fig 2. Indonesia's constitutional hierarchy (Source: Dwiputrianti, 2011: 15) 
As the highest auditing agency, BPK has the same position as the executive, legislative, and judiciary. BPK has a mandate to oversee the management and accountability of public finances. BPK audits are conducted on central and local governments, state-owned enterprises, and other agencies that manage public finances. Such audits can be carried out in the form of financial audits, performance audits, and special purpose audits[6]. As an institution mandated to oversee the management and accountability of public finances, BPK aims to contribute to the preparation of SGDs implementation in Indonesia by conducting a cooperative audit of the readiness of SDGs Implementation under IDI. By providing constructive recommendations, BPK has an imperative part in supporting the accomplishment of the SDGs plan in Indonesia. Next, the analysis model used by BPK will be explained in conducting the SDGs audit.

\subsection{Data Analysis Through Geographic Information System (GIS)}

Geographic Information System (GIS) may be a framework outlined to capture, store, control, analyze, organize and show all sorts of geographic information. The acronym GIS is now and then utilized as a term for geological data science or geospatial data considers. In a simple sense, a geographic information system can be concluded as a combination of cartography, factual examination, and innovation database frameworks (database). GIS cannot be isolated from spatial information, which is information that alludes to positions, objects, and the relationship between them in soil space. Spatial information is one of the things of data in which there's data approximately the soil counting the earth's surface, underneath the earth's surface, waters, seas, and underneath the air[7].

\subsection{Spatial Analysis}

a. Reclassification

Reclassification is analysis to change or simplify data using the automatic reclassification method, where the computer will perform automatic reclamation, manual reclassification, where the data will be reclaimed based on user input. An example of reclassification is if at the time of making the map it is classified that each protected forest area is marked with a value of 10 . So, assuming the value of protected forest area $=1$, then reclassification has been carried out on the creation of a new map where the non-protected forest area is worth $=0$. Operation This reclassification uses the Boolean operator $(1,0)$.

b. Buffering and Neighborhoods Functions

There are various functions in GIS, which allow spatial entities to influence neighborhoods and thus affect the characteristics of an entity.

c. Integrating Data - Map Overlay

Data integration is the capacity to combine information from two diverse sources, employing an outline overlay method, so that the comes about can be utilized as analysis material. An overlay could be a modern information set that's combined with two or more information sets, coming about in an unused layer. There are contrasts within the utilize of outline overlay methods between raster and vector.

d. Spatial Interpolation

Spatial interpolation is the strategy of assessing property values in a closed region, by existing perceptions.

e. Analysis of Surfaces

- Calculating Incline and Viewpoint

- The slant is the steepness or slope of a unit which is as a rule measured as a point in degrees as a rate. Perspective is the course calculated from degrees north. Permeability 
Examination is the distinguishing proof of zones that can be seen from a certain point on the territory surface.

f. Location Analysis

Location analysis also applies where a suitable network data set is not accessible or is as well huge or costly to utilize, or where the area calculation is exceptionally complex or includes analyzing or mimicking a huge number of elective setups.

g. Network Analysis

GIS-based network analysis can be utilized to address an assortment of down-to-earth issues such as course determination and office area (a central theme within the field of operations inquiries about, and issues including streams such as those found in hydrological, and transport investigate. In numerous cases, area issues are network-related and in this way tended to with instruments planned for this reason, but in others, existing systems may have small or no significance or may not be practical to consolidate within the modeling handle. Issues that are not particularly organized compelled, such as modern street or pipeline steering, territorial stockroom areas, cellular phone shaft position, or rustic community wellbeing care location choice, can be successfully analyzed (at slightest at first) without reference to the analyst's physical arrange.

\subsection{Analytical Modeling in GIS}

Theoretically, objects in geographic space can be separated into two sorts of data. The primary sort related to their area on soil is way better known as spatial information. The moment sort distinguishes non-spatial properties of objects and is alluded to as trait information. Attribute data can be measured in the nominal, ordinal, interval, and ratio scales. These attributes are usually used by non-spatial scientists to describe the classification of objects according to the attribute values they have.

Geographical classification traditionally recognizes the division of all objects into four classes, namely points, lines, areas, and surfaces. Distance or length is a basic geographic dimension, and spatial objects can be classified according to the number of length dimensions they have, for example, zero for points, one for lines, two for areas, and three for surfaces. It's just that GIS has not been able to handle temporal data even though it is recognized that the time dimension is an important thing in GIS applications.

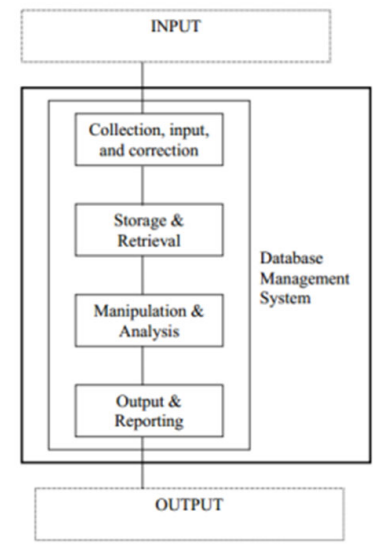

Fig 3. GIS Process Flow (Source: Irwansyah,2013: 65) 


\subsection{Basic Forms of GIS Models}

The shape of the GIS model has four main components, namely:

a. Correction, input, and collection are operations that emphasize receiving/collecting data in the system, including scanning, manual digitization, online retrieval from other database systems, and keyboard entry. At this stage, the first digital map is built.

b. Storage and retrieval mechanisms including control of data storage facilities in memory, diskettes, and retrieval mechanisms to serve the needs of the next three system components.

c. Manipulation and analysis display all available techniques in digital model transformation using mathematical means. This is the essence of GIS, and what sets it apart from Computer-Assisted Cartography. A set of information preparing calculations is accessible for changing spatial information, and the comes about of information control can be included in a computerized database and connected to a modern visualization of an outline.

d. Output and reporting include the process of removing data from the system in a computer or other form that can be read. This is the stage where digital database users can selectively create new analog maps.

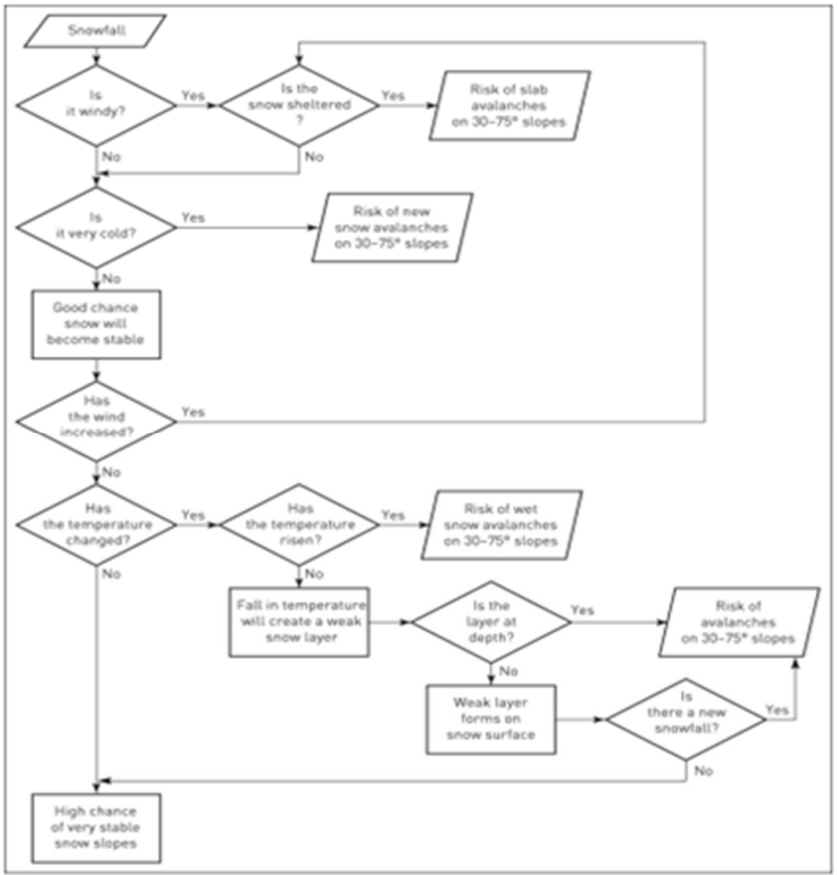

Fig 4. Conceptual Model (Source: Irwansyah,2013: 67)

The classification of the process model in geographic information systems is divided into three, namely:

a. Natural analog models, using actual events or real-world objects as the basis for model construction.

b. Conceptual models are usually depicted in graphical or verbal form and illustrated in pictures of quantitative and qualitative interactions between real-world features or words. 
The mathematical model method uses a variety of techniques including optimization, stochastic, and deterministic methods.

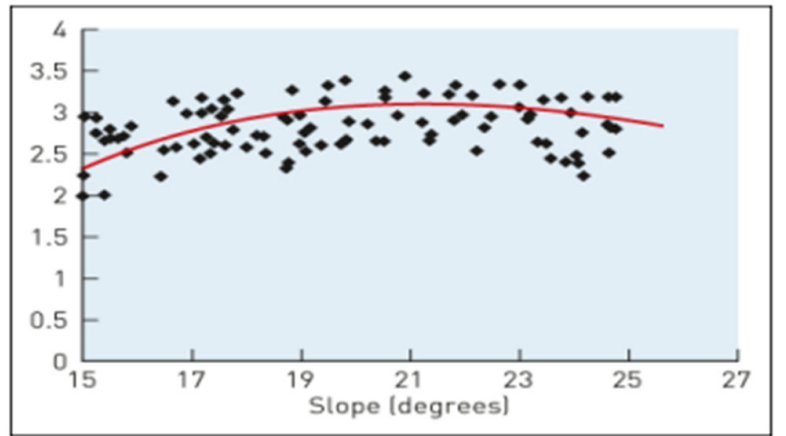

Fig 5. Mathematical Methodology Model (Source: Irwansyah,2013: 68)

\subsection{Physical and Environmental Modeling Process}

The physical and environmental modeling process is the most widely implemented modeling process using geographic information system tools. Heywood describe three examples of physical and environmental modeling, namely modeling exhaust gas calculations (emissions), modeling forest fires, and decreasing variables for determining watersheds using DEM data. [8]. In exhaust gas modeling, spatial entities in the form of lines, areas, and points in the form of vector data are used to map geographic objects of each industrial stack, vehicles traveling roads and residential areas, and other built areas. The data in the next model is converted in an area of $1 \times 1 \mathrm{~km}$ which is then used to calculate the total average exhaust gas per area of $1 \times 1 \mathrm{~km}$.

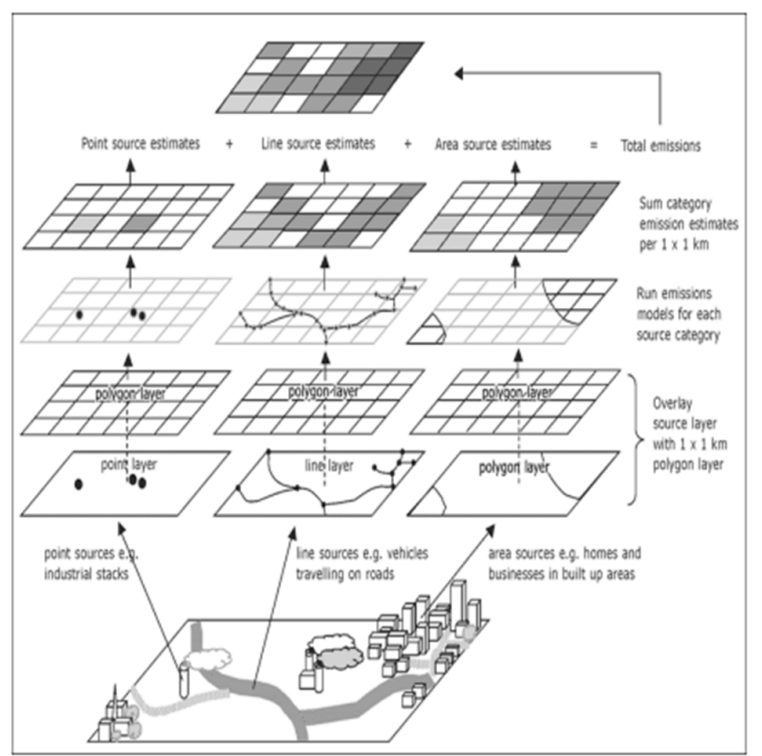

Fig 6. Methodology for estimating exhaust gas (emissions) with GIS tools (Source: Irwansyah,2013: 69) 


\subsection{Human-Environment Modeling Process}

Two main models are often used in the process of modeling human behavior with geographic information systems, namely: Gravity and spatial interaction models. Spatial interaction models are models used to predict the location of activities and help understand the movement of materials, information, and people. The figure below is an example of modeling the human environment specifically to predict sales at a chain store in Toronto, Ontario, Canada).

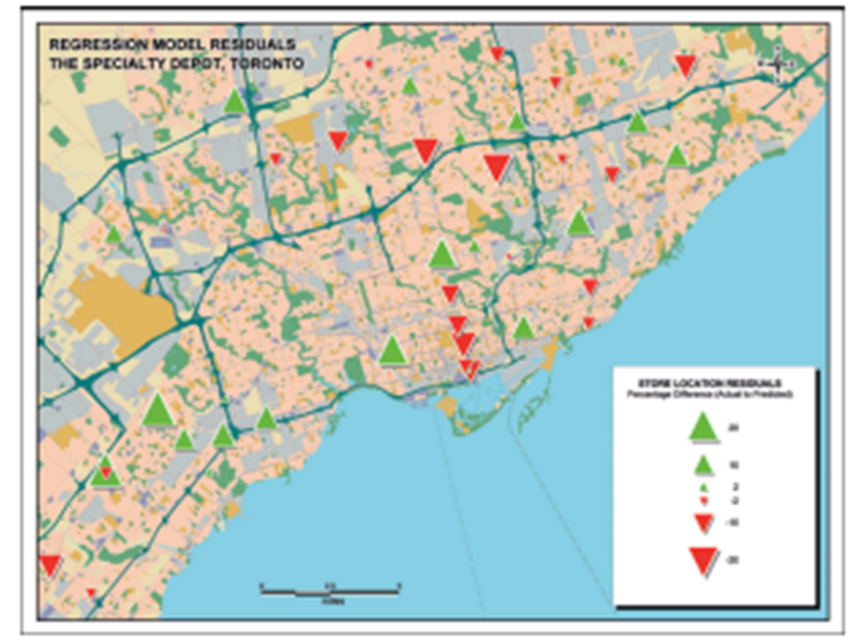

Fig 7. Percentage between actual and predicted sales at The Specialty Depot's store network in Toronto, Ontario, Canada (Source: Irwansyah,2013: 72)

As for the gravity model, it is generally used for distance decay synthesized from Newton's law of gravitation to calculate the relative interaction between multiple different destinations or cities.

\subsection{Decision-Making Modeling Process}

The decision-making modeling described by Heywood is a Multi-Criteria Evaluation (MCE) technique which is an additional technique to replace the commonly used map overlay technique. MCE technique is a technique of combining spatial data according to its importance to make a decision. According to Heywood there are four stages to implementing MCE, especially using raster data, namely:

a. Selection criteria,

b. Standardize the value of each criterion

c. Allocate the weight of each criterion and

d. Applying the MCE algorithm

In the figure below, you can see the stages of applying weighting to each criterion in a home purchase decision-making system that uses raster data. 


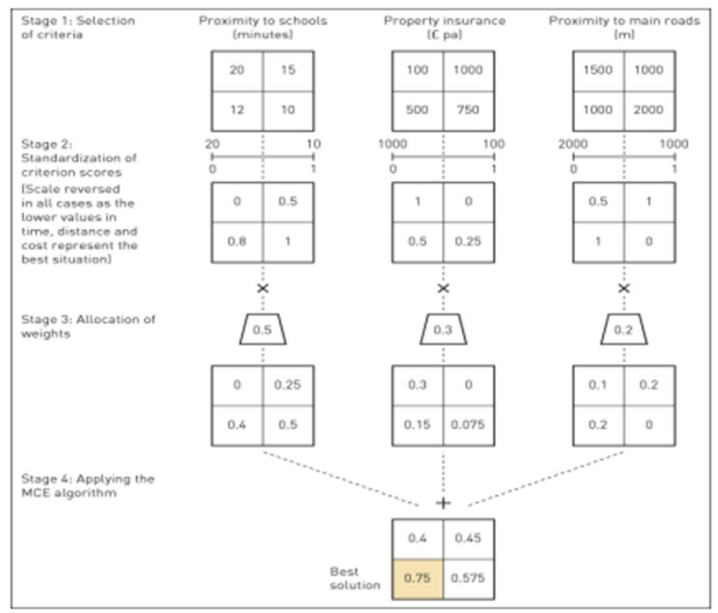

Fig 8. Application of weighting criteria to raster data (Source: Irwansyah,2013: 73)

In addition to using MCE techniques in decision-making modeling, Fuzzy GIS techniques can also be an alternative in analytical GIS modeling. Heywood et al, 2006 described an example of analytical modeling with GIS that utilizes fuzzy techniques for applications to identify areas of high crime in the Leeds area of the United Kingdom. The fuzzy technique in GIS allows analysis to be carried out in more detail, especially to overcome the effect of uncertainty on realworld conditions.

\subsection{The Communication of Information in Audit Reports}

How auditors communicate information in audit reports to the stakeholders is additionally a portion of surveying the quality of data. It is essential that the review reports of an review institution meet three criteria, specifically: [9]

a. They are communicated clearly and justifiably,

b. They have exact and instructive organizing, and

c. They are convenient.

BPK reports within the past were troublesome to get it since of as well numerous specialized budgetary, bookkeeping and auditing terms. These were troublesome to get it for partners with no information or foundation in back and bookkeeping. Since review change, BPK has provided guidelines for inspectors to supply clear and reasonable reports for stakeholders. In addition, BPK gives rundown reports that partners discover less demanding to studied, not slightest since they contain a glossary of specialized terms.

In terms of the review report organize, sometime recently change, BPK audit reports were troublesome to examined, were as well complicated, were long and were ineffectively organized. Since audit change, BPK reports are displayed more essentially and accurately in a user-friendly way with a rich format, pictures, graphs, and charts. This has ensured numerous stakeholders are more interested to studied BPK reports. 


\section{The SDGs Audit Approach Used by BPK}

With the outbreak of the COVID-19 pandemic throughout the world, BPK has begun to make new innovations related to the use of the SDGs audit model. The impact of the Covid-19 pandemic has affected various aspects of life that brought the world community into the VUCA (volatility, uncertainty, complexity, and ambiguity) era and jeopardized national and global efforts to achieve the SDGs. (The presentation of Agung Firman Saputra, Chairman of BPK, in the virtual conference 'The 1st Global Parliamentary Meeting on Achieving the SDGs) [10]

In order to maintain the sustainability of program implementation and to ensure that the SDGs and 2030 Agenda programs are successful, BPK has adapted four INTOSAI approaches, namely:

a. Assessing the readiness of SDGs implementation;

b. Conduct a performance audit;

c. Assessing and supporting the implementation of SDGs 16 and 17, and

d. Become a model of transparency and accountability.

The approach adopted, then interpellated and used by BPK in conducting Risk-based Comprehensive Audits, is divided into several approaches, namely:

a. Implement a thorough audit,

b. Selecting high-risk audit areas,

c. Combining three types of audits, namely financial audits, performance and compliance

(compliance), and

d. Optimizing the use of Big Data Analytics.

\section{Conclusion}

Innovation from the audit carried out by BPK related to the implementation of the SDGs agenda is very much needed. This is suspected to be a challenge in every field which tends to vary causing the definition of audit among UN member countries that implement the SDGs, have various interpretations. Therefore, the initiative from BPK by conducting an audit using the Geographic Information System method coupled with Social Network Analysis (Gephi) greatly assisted the implementation of the external audit carried out.

However, this audit method is not yet perfect, so further developments are needed and must be tested with various challenges in the field. What BPK has done should open the door for further innovation from this method, so that in the future this method when it has been perfected can bring many benefits to the implementation of the SDGs agenda that is accountable, transparent, and beneficial to bring prosperity to all mankind.

\section{References}

[1] United Nations. United Nations: Department of Economic and Social Affairs. 2021. 19 October 2021. https://sdgs.un.org/goals

[2] Bappenas. SDGs $\quad$ Dashboard. $2021 . \quad 19 \quad$ October 2021. http://sdgs.bappenas.go.id/dashboard/\#!/pages/landingPage.html

[3] INTOSAI. INTOSAI - International Organization of Supreme Audit Institutions. 2021. 17 October 2021. https://www.intosai.org/focus-areas/audit-standards

[4] INTOSAI Development Initiative.: ISAM - IDI's SDGs Audit Model. Pilot Version, pp. 8-15 (March 2020) 
[5] BPK RI.: Performance Audit Report of the Preparedness for Implementation of SDGs in Indonesia, pp 9-13. BPK RI (2018)

[6] Septiana Dwiputrianti.: Role of the Indonesian Supreme Audit Institution (BPK) in Financial Transparency and Performance Accountability, pp 15-16. in Innaugural International Workshop for Young Scholars in Public Policy and Administration Researchin Xiamen, China (2011)

[7] Edi Irwansyah.: Sistem Informasi Geografis: Prinsip Dasar dan Pengembangan Aplikasi, pp 63-72. Digibooks (2013)

[8] Heywood. Et al.: An Introduction to Geographical Information Systems. 4rd Edition, pp 73-109. Pearson Education Limited (2011)

[9] Septiana Dwiputrianti.: How Effective is the Indonesian External Public Sector Auditing Reports Pre and Post Audit Reform for Enhancing Performance of Public Administration?, pp 10-11. The International Review of Public Administration (IRPA), the Korean Association for Public Administration (KAPA) (ISSN 12294659) (2011)

[10] BPK RI. Ketua BPK Memberikan Intervensi pada "First Global Parliamentary Meeting on Achieving the SDGs". Jakarta, 30 September 2021. 21 October 2021. https://www.bpk.go.id/news/ketua-bpkmemberikan-intervensi-pada-first-global-parliamentary-meeting-on-achieving-the-sdgs 